\title{
Named and Unnamed Spaces: Color, Kin, and the Environment in Umpila
}

\section{Clair Hill}

Clair Hill is a linguist with a special interest in Australian Aboriginal languages, in particular those of the Cape York

Peninsula region. She

is currently working on the Umpila-Kuuku Ya'u-Kaanju language group for her doctoral research at the Max

Planck Institute for Psycholinguistics and University of Leuven. clair.hill@mpi.nl
ABSTRACT Imagine describing the particular characteristics of the hue of a flower, or the quality of its scent, or the texture of its petal. Introspection suggests the expression of such sensory experiences in words is something quite different than the task of naming artifacts. The particular challenges in the linguistic encoding of sensorial experiences pose questions regarding how languages manage semantic gaps and "ineffability." That is, what strategies do speakers have available to manage phenomena or domains of experience that are inexpressible or difficult to express in their language? This article considers this issue with regard to color in Umpila, an Aboriginal Australian language of the Paman family. The investigation of 
color naming and ineffability in Umpila reveals rich associations and mappings between color and visual perceptual qualities more generally, categorization of the human social world, and the environment. "Gaps" in the color system are filled or supported by associations with two of the most linguistically and culturally salient domains for Umpila - kinship and the environment.

KEYWORDS: color, visual perception, semantic gaps, analogy, kinship, semantic categories

\section{Introduction}

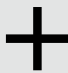

The nature and structure of color has been the focus of extensive work and is central to the debate on linguistic relativism/universalism (Berlin and Kay 1969; Hardin and Maffi 1997). In contrast, consideration of the linguistic encoding and cultural relevance of non-chromatic visual qualities has not received much attention to date. Likewise, the study of semantic gaps or "ineffability" in color naming has not been an area much considered - unsurprisingly given that such exploration does not sit well with core claims of universal constraints on color naming and views of color as an exhaustively named and unitary domain. These two underexplored considerations are interrelated in the Umpila data reported in this article. Some types of ineffability explored here demonstrate cross-domain associations such as the use of shared linguistic strategies in color and plant reference. This in turn highlights speaker's beliefs about various visual perceptual qualities organizing two kinship groups.

\section{The Language and People}

Umpila is a Paman language (Hale 1964) spoken on the northeastern coast of Cape York Peninsula, Australia. Prior to non-indigenous settlement, this dialect complex included six or more varieties (Thompson 1988). Throughout this article the dialect group will be collectively referred to as Umpila. Today, the language is moribund and an English-lexifier creole is the vernacular. Only three of the dialects, Umpila, Kuuku Ya'u, and Kaanju, are still spoken by a handful of elderly people. Traditionally, the groups that formed this linguistic-social complex were semi-nomadic hunter-gatherers. Nowadays most Umpila people reside in Lockhart River Aboriginal Community; however, they maintain connections to their traditional lands and some coastal hunter-forager practices remain a part of daily life.

The data presented in this article are from all three still-spoken varieties. Much of the following discussion focuses on results from 
a series of formal tasks exploring color categorization, undertaken on field trips by the author in 2007 and 2008. This task based investigation has been heavily informed by other types of data ethnographic observation of linguistic and cultural practices, narrative and discourse material, and elicited data.

\section{Two Types of Gaps or Low Specificity in Perceptual Domains}

In Umpila there are two broad types of lexical semantic encoding of simple perceptual experiences, each of which is typically associated with whole perceptual domains (vision, audition, olfaction, taste, touch). Most domains typically employ all-purpose vocabulary. This can be readily applied across an entire perceptual domain, but lacks the semantic precision of a domain-specific lexicon. The most commonly employed all-purpose lexicon are antonym pairs like good-bad (e.g. something is good or bad to touch, smell or taste) and big-small (e.g. the shape or sound is big or small). In contrast, there are perceptual domains which have established systems of domain-specific specialized lexicon - the ineffability here is that such systems do not cover an entire domain's perceptual space. In such cases speakers fall back on using ad-hoc strategies, generic terms, or struggle to fill these spaces with any vocabulary item at all (non-responses in stimuli-based elicitation was not uncommon). Color is an example of this type of domain, and will be the focus of the ensuing discussion.

\section{The Color System}

Umpila has a three-term black-white-red (thungku(thungku)-pulpichipulpanchi) color system. Three-term systems are towards the more minimal end of the Berlin and Kay (1969) implicational scale (stage 2 language), with only two-term systems occurring earlier in their posited evolutionary sequence. In Umpila color words are part of the nominal subclass and typically function as attributive adjectives. Thungkuthungku 'black,' pulpichi 'white,' pulpanchi 'red' are the most frequently employed realizations of these forms. They are also alternatively produced as thungku 'black,' pulpul 'white,' and pulpan(a) 'red.'

Pulpanchi-pulpana is the only one of the three that is potentially analyzable: speculatively, it can be related to the forms pulpa- 'to swell up,' pulpan 'tail,' and pulpan(a) 'sore, lump'1 via associations between redness, swelling, and protrusions. The -chi ending on pulpichi 'white' and pulpanchi 'red' is the comitative suffix, which marks 'having, accompaniment' and is often employed to derive nouns from other noun subclasses. Reduplication (partial or full repetition), as in thungkuthungku 'black,' is a common means of expressing intensification and for deriving adjectives from other nominal stock. 


\section{Color Naming Task: Unnamed Spaces and Individual Variation}

The range of the black-white-red forms across the color spectrum, and color naming practices more generally, was explored using eighty Munsell color chips in a number of tasks. This set of chips consisted of twenty equally spaced hues at four degrees of brightness. The core task was a simple naming task (Majid and Levinson 2007; part of the suite of tasks in Majid 2007) that elicited vocabulary for the chips one-by-one. This was undertaken with eleven speakers - five Umpila, three Kuuku Ya'u, and three Kaanju.

The most striking aspect of the results was that the three-term system, along with other ad-hoc resources speakers adopted, did not exhaustively name the color spectrum. The mode map image (Figure 1) shows the mapping of the color space based on the cross-speaker majority response to each chip. In color naming (and to a lesser degree in the free-sort task - see below), speakers left the majority of the color space unnamed, much of the time producing "non-responses," such as manthala-kanyu 'name-without,' ulmpaya 'nothing,' ngampa pithanchi 'don't know.'2 The "unnamed" space is represented by the shaded area in Figure 1. During the task some speakers even reflected on the gaps in the naming of the color spectrum. One Kaanju speaker commented: "well we only got three [words] and that's alright, and you know I take a fancy for everything you show, but I couldn't do it, you know." In existing descriptions of color systems languages that do not have terms partitioning the entire color spectrum are rare and poorly accounted for (see Kay and Maffi 1999; Levinson 2000). ${ }^{3}$

Spaces in the color spectrum unnamed by conventionalized color vocabulary were not entirely filled by the types of "non-responses" listed above. There was also a smattering of mostly one-off responses by individual speakers (not represented in Figure 1, which depicts the overall results). Such responses included direct underived reference to body parts, time of day, meteorological phenomena, animals, plants, and places, e.g. thalmpuy 'lips,' ngulku 'night time,' mil'achi' 'shooting star,' miil'a pinga/ingkawu '(like a) flower,'

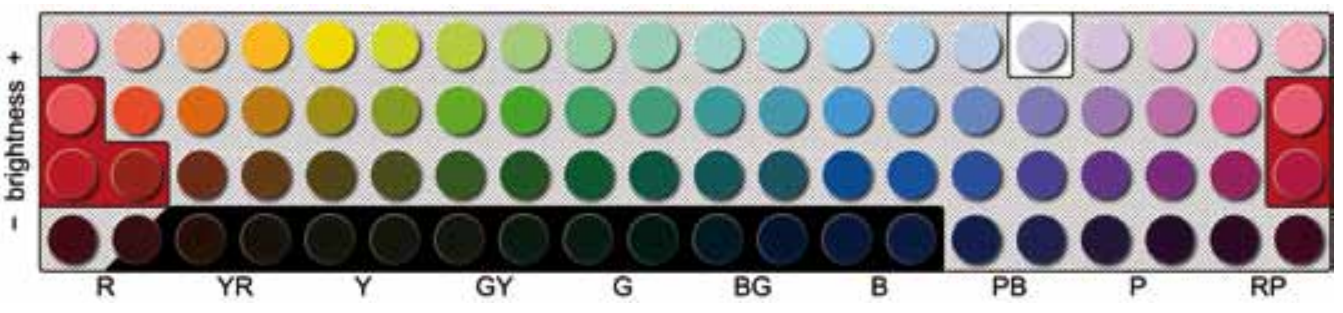

Figure 1

Umpila naming task mode map. The figure shows Umpila naming task data mapped onto a Munsell color grid. 
puuta 'red ochre,' yangki 'carpet snake species,' kuungangunama 'coconut palm species/place,' kanthanhampu 'palm species/place/ ethnonym.'

\section{Color Free-sort: Kin Dyadic Constructions as an Analogy Making Tool}

In addition to the color naming, four speakers completed a free-sort task with the same eighty chips. In this task the stimuli were spread out on a table and speakers were asked to group together the chips based on similarity in any way they wished. The discussion here will focus on just one aspect of the results - the use of a kin dyadic construction to fill in areas of low specificity in the color spectrum. Two speakers independently of each other used a special kin reference strategy to place several of the sorted groups into a kin relationship, in particular a grandmother-grandchild relationship.

Kin dyad constructions form expressions denoting pairs of a type from kinship terminology, e.g. pairs of siblings, husband-wife pair, mother-child pair (Evans 2006; Merlan and Heath 1982). There are a number of kin dyad construction types in Umpila. The construction used by both speakers in the free-sort is miimi kuunchi formed from miimi 'maternal grandmother' and kuunchi 'relative. ${ }^{5}$ As is the case with all dyad constructions in Umpila, this expression overtly names one member of the pair while invoking the other member.

To take you through one of these free-sort tasks (Figure 2): the speaker (Umpila dialect) created six groups. Three were labeled using the black (15 chips), white (10), and red (8) color terms, one group with a miil'a pulpanchi 'like red' similative construction (8), and two groups were unlabeled $(10,29)$. These piles were ordered from light to dark across the table, the exception being the largest unnamed group which was moved off to the far left. Having completed the grouping the speaker proceeded to pair consecutive areas of the sort and color spectrum using the miimi kuunchi expression: pairing the 'red' group as grandmother with 'like red' as grandchild; 'black' as grandmother to the smaller unlabeled grandchild group; and 'like red' grandmother to 'white' grandchild.

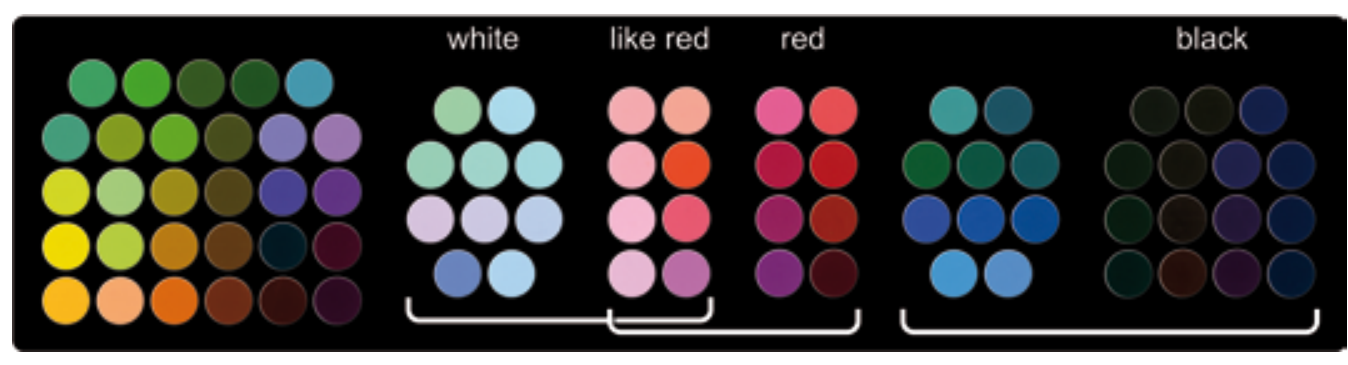

Figure 2

Color free-sort. The figures are in color in the online version of the article. 
In considering why speakers adopt such a strategy, let us turn to one of the most linguistically and culturally salient domains for the Umpila - the environment. This miimi kuunchi kin dyad is employed as a conventionalized analogy for creating associative relationships in the natural world, particularly between plants (Chase and von Sturmer 1980). It has been noted in many parts of Aboriginal Australia that plants and animals can be referred to as "mates" (companions) on the basis of various connections, e.g. mythological association, totemic affiliation, physical resemblance, habitat relationship, symbiotic relationship (Chase and von Sturmer 1980; Evans 1997). The miimi kuunchi expression is one of the linguistic strategies for encoding a "mateship" relation in Umpila. It is used to construct within category relationships, typically between minimally distinct plant species. ${ }^{6}$ As with the color free-sort, this expression maps across named and unnamed "spaces" in the plant domain (example $A$ in Table 1), as well as between two unnamed plants or between two named plants (B and $C$ in Table 1 ).

It is easy to infer two patterns potentially motivating the grandmother-grandchild mapping onto the color groups in the freesort: the speaker places a named color as grandmother to groups which are either unnamed by a proper color word (e.g. 'like red' construction) or unlabeled groups, and/or places darker hues in a grandmother relationship to lighter grandchild hues (e.g. 'like red' as grandmother to 'white'). Despite the patterns in this free-sort, further investigation suggested that the use of the kin dyad construction in the color domain is not conventionalized in the same way it is for plant references. Structured elicitation where speakers were asked to make dozens of free and set pairs of color-kin associations in various ways indicated that speakers in using this kin dyad are most

Table 1 Miimi kuunchi kin dyad.

Name relation

Minimally distinct plants*

A. Named-unnamed Fruit-bearing trees: ngathalngki (Vitex glabrata R.Br.) grandmother to unnamed tree (Lagerstroemia archeriana F.M.Bailey var. archeriana)

B. Both unnamed

Spurges: Chamaesyce atoto (G. Forst.) Croizat grandmother to Chamaesyce filipes (Benth.) D.C.Hassall ${ }^{\star *}$

C. Both named

Fiber plants: yapathara (Dianella (species unknown)) grandmother to watul (Xerotes longifolia (Labill) R.Br.)

${ }^{*}$ Chase (1976; plant taxonomy updated: Australian Plant Names Index, Australian Virtual Herbarium); Hill field notes, 2008.

${ }^{* \star}$ Chamaesyce filipes is not generally found in this region. This identification may be incorrect, and if so it is most likely to be another Chamaesyce species of close resemblance. 
likely not drawing on conventionalized cross-speaker shared colorkin mappings. While speakers produced pairings readily and with ease, these pairings did not have cross-speaker systematicity, and were, for instance, not constrained by a simple light-dark mapping to indicate generational or gender differences. However, these sessions nicely demonstrated that the miimi kuunchi expression is a well-established analogy-making tool available to speakers. The kin system is a multidimensional space with a set of established oppositions that encode relationships of attraction and affinity, taboos and avoidance. Such oppositions can be readily co-opted to help support naming and categorization and to fill semantic gaps, both in a highly linguistically and culturally salient domain like the environment, but also when interacting with very unfamiliar stimuli in this case decontextualized color chips.

\section{"Kaapay This Moving Water One, Them One Moving One": A Note on Kuyan and Kaapay Moiety Classification}

The use of words for natural phenomena in color naming was briefly discussed earlier. Interestingly, color is not the only domain in which the Umpila draw on associations between the environment and visual qualities. Here, we turn the discussion from the use of kinship terminology in color categorization to culturally significant beliefs about the role of visual perceptual properties in the organization of two kinship groups. Umpila has patrilineal moiety descent groups referred to as kuyan and kaapay. Traditionally, moiety classification was a key part of the social rules governing marriage, with each member of the group obliged to marry someone from the other moiety. ${ }^{7}$ As is usual in the Aboriginal Australian context, this classification system incorporates much of the natural world: major plants and animals, and all tracts of land (Chase 1980). Umpila speakers believe that there are underlying physical differences that motivate or underpin this categorization. Despite determination via patrilineal descent, speakers talk of a person's moiety as indicated by physical appearance, variously invoking features of shape and distinctiveness of lines on the palm of the hand, coloring of hair and skin, hair type (Chase 1980; Hill field notes, Lockhart River, 2008; Thomson 1933). For tracts of land, speakers appeal to properties like the presence of certain plant species, intensity of bark/leaf coloration, topographical features, and water source types (Chase 1980; Hill field notes, Lockhart River, 2008).

The belief that various qualities or essential features underlie moiety classification, while steadfastly held, is still somewhat of an ineffable concept. Speakers struggle to articulate the particulars of these shared physical traits. Spontaneous comments appealing to these distinctions emerge naturally in interaction with the world, but different speakers appeal to different qualities at different times, and when queried they frequently fall back on the phrase that such 
variously classified people-plants-animal-land simply look another kind. ${ }^{8}$

To what degree do color or other visual perceptual qualities play a role in the properties associated with kuyan and kaapay? A simple photo-sorting and elicitation task with a set of forty-one images was undertaken with four speakers, and provided some insights on this point with regard to landscape. The photos featured attributes of the local environment speakers had previously spontaneously invoked in their interpretation of kuyan and kaapay land estate classification, e.g. ripples/textures of earth/sand/stone, leaf types, bark patterns, cloud formations.

In the sorting and commentary, color appeared to play little or no role, instead illuminance was a key organizing factor. Images selected as kuyan were repeatedly characterized as: pulkapulka (ashes.REDUP) 'dirty/dusty/like ashes,' ngulmana 'dusk,' dull. Kaapay classified images were: striped, pachala 'daybreak, bright,' chanchi 'attractive young person,' (malngal)malngala 'heat haze, mirage, glare.' In particular, a number of images featuring moving water and light refracting off water were consistently classified as kaapay. One speaker noted: "kaapay this moving water one, them one moving one." The same speaker commented for another image: "malngala ['heat haze, mirage, glare'], all this one here, kaapay ... this one here, like river running, them wan him thing inside now [indicating refracted flecks of light]." The role of illuminance is reminiscent of observations made for other Australian groups: Jones and Meehan (1978) comment on the importance of brilliance and animation in color categorization in Gidjingali; Wierzbicka (2008) on Warlpiri people's preoccupation with "shining" entities; Morphy's (1989) paper on Yolngu aesthetics describes the significant role of bir'yun 'brilliance, shimmering' in Yolngu painting and ritual; in Leeding (1989) the presence and absence of luster is posited as a criterion for noun-class assignment in Anindilyakwa; and see Sutton and Snow (in press) for a discussion of the cultural significance and associations of iridescence with power, life-giving forces, and danger in Aboriginal Australia and beyond.

\section{Summary and Some Closing Comments}

Color is not a highly lexically elaborated domain in Umpila. There is a small (three-term) color word inventory, and color naming and free-sorting tasks demonstrated a large unnamed area in the color spectrum not covered by the three-term system. Some of the gaps in the "unnamed" color space were filled by ad-hoc responses by speakers to natural phenomena, such as plants, animals, and places. These types of association may have their basis in folk beliefs that various qualities or essential features (e.g. illuminance) motivate and organize moiety classification. Such properties have key cultural import being part of beliefs about a pervasive classification system for speakers. In Umpila abstract color appears to be less relevant 
(less linguistically elaborated and less culturally significant) than these non-chromatic visual qualities (see Conklin 1955; Jones and Meehan 1978 for similar points).

Via a color free-sort task another connection between social organization and visual perceptual properties emerged. The miimi kuunchi construction, a resource drawn from the kinship system that is most typically applied to plants, was used to support naming and categorization of colors. Kin dyad constructions that only overtly name one kin member while invoking the other pair member make for a particularly apt analogy for mapping between named and unnamed spaces. The use of such a construction to help bolster lexical gaps in another system reflects both the relational nature of kinship systems and their salience in Aboriginal Australia.

This article reports a rich set of interrelations between visual perceptual qualities, the natural environmental domain, and the kinship system in Umpila. This finding emphasizes the importance of research on language of the senses to take a culturally situated approach and to be sensitive to forces within the language and culture that may shape and interact with multiple domains and units of semantic organization.

\section{Acknowledgments}

I am greatly indebted to the Umpila, Kuuku Ya'u, and Kaanju speakers for teaching me their language. This research was undertaken in the Language of Perception study (within the Categories across Language and Cognition project) at the Max Planck Institute for Psycholinguistics. Special thanks for discussion and other assistance to Niclas Burenhult, Athol Chase, Ludy Cilissen, Stephen Levinson, Asifa Majid, John Pritchard, Lila San Roque, and Jean-Christophe Verstraete, and thanks for feedback received from members of the audience at the European Australianists Workshop 2009. I am grateful for support from the Hans Rausing Endangered Languages Project and the Max Planck Gesellschaft.

\section{Notes}

1. Zero derivation, employing an unconverted form in multiple lexical categories, is common in Umpila.

2. The potential effect of the language loss/change situation on color categorization in Umpila speakers is currently under investigation. Preliminary work suggests that the naming gaps present in the data are not simply a result of the moribund situation, e.g. semispeakers tend to name more of the color space than proficient speakers. Additionally, nearby language Kuku Yalanji has a similar black-white-red system with the "leftover" area featuring high interspeaker variation (characterized by Kay and Maffi (1999) as "Bk, W, R, plus confusion").

3. In Kay and Maffi (1999) terms, Umpila is a non-partition language.

4. In Umpila orthography an apostrophe represents a glottal stop. 
5. This construction does not always have a dyadic reading. In some contexts kin-term + kuunchi can function somewhat like genitive case or a third-person possessive pronoun.

6. This is noted by Sutton (1980) as being one of the usual types of "mateship" associations.

7. Nowadays, knowledge of this classification system is limited to older generations, and it no longer appears to play a significant role in mediating social relations.

8. Strikingly, this phrase was also noted in relation to moiety classification in early anthropological work on the region (Thomson 1933).

\section{References}

Berlin, Brent and Kay, Paul. 1969. Basic Color Terms: Their Universality and Evolution. Berkeley, CA: University of California Press. Chase, Athol. 1976. ECY-Plants Field Notes, 1975-6.

Chase, Athol. 1980. "Which Way Now? Tradition, Continuity and Change in a North Queensland Aboriginal Community." Ph.D. thesis, University of Queensland.

Chase, Athol and von Sturmer, John. 1980. "Anthropology and Botany: Turning Over a New Leaf." In Bruce Rigsby and Peter Sutton (eds), Papers in Australian Linguistics No. 13: Contributions to Australian Linguistics. Canberra: Pacific Linguistics.

Conklin, Harold. 1955. "Hanunoo Color Categories." Southwestern Journal of Anthropology 11(4): 339-44.

Evans, Nicholas. 1997. "Sign Metonymies and the Problem of Flora-Fauna Polysemy in Australian Linguistics." In Darrel Tryon and Michael Walsh (eds), Boundary Rider: Essays in Honour of Geoffrey O'Grady, pp. 133-53. Canberra: Pacific Linguistics.

Evans, Nicholas. 2006. "Dyad Constructions.” In Keith Brown (ed.), Encyclopedia of Language and Linguistics, Vol. 4, pp. 24-7. Oxford: Elsevier.

Hale, Kenneth. 1964. "Classification of Northern Paman Languages, Cape York, Australia: A Research Report." Oceanic Linguistics 3(2): 248-64.

Hardin, Clyde and Maffi, Luisa (eds). 1997. Color Categories in Thought and Language. Cambridge: Cambridge University Press. Jones, Rhys and Meehan, Betty. 1978. "Anbarra Concept of Color." In Lester Richard Hiatt (ed.), Australian Aboriginal Concepts, pp. 20-39. Canberra: AIAS Press.

Kay, Paul and Maffi, Luisa. 1999. "Color Appearance and Emergence and Evolution of Basic Color Lexicons." American Anthropologist 101(4): 743-60.

Leeding, Velma. 1989. "Anindilyakwa Phonology and Morphology." Ph.D. thesis, University of Sydney.

Levinson, Stephen C. 2000. "Yélî Dnye and the Theory of Basic Color Terms." Journal of Linguistic Anthropology 10(1): 3-55. 
Majid, Asifa (ed.). 2007. Field Manual Volume 10. Nijmegen: Max Planck Institute for Psycholinguistics.

Majid, Asifa (ed.) and Levinson, Stephen C. 2007. "The Language of Vision I: Colour." In Asifa Majid (ed.), Field Manual, Vol. 10, pp. 22-5. Nijmegen: Max Planck Institute for Psycholinguistics.

Merlan, Francesca and Heath, Jeffrey. 1982. "Dyadic Kinship Terms." In Jeffrey Heath, Francesca Merlan and Alan Rumsey (eds), The Languages of Kinship in Aboriginal Australia, pp. 107-24. Sydney: Oceania Linguistic Monographs.

Morphy, Howard. 1989. "From Dull to Brilliant: The Aesthetics of Spiritual Power among the Yolngu." Man 24(1): 21-40.

Sutton, Peter. 1980. "Linguistic Aspects of Ethnobotanical Research." In Bruce Rigsby and Peter Sutton (eds), Papers in Australian Linguistics No. 13: Contributions to Australian Linguistics, pp. 103-14. Canberra: Pacific Linguistics.

Sutton, Peter and Snow, Michael. In press. "Iridescence." In Diana Young (ed.), Re-materializing Colour. Oxford: Sean Kingston Publishing. Forthcoming.

Thompson, David. 1988. Lockhart River "Sand Beach" Language: An Outline of Kuuku Ya'u and Umpila. Darwin: Summer Institute of Linguistics.

Thomson, Donald F. 1933. "The Hero Cult, Initiation Totemism on Cape York." Royal Anthropological Institute Journal 63: 453-537. Wierzbicka, Anna. 2008. "Why there are no 'Colour Universals' in Language and Thought." Journal of the Royal Anthropological Institute 14(2): 407-25. 